\title{
Electrospun Nanocomposite Fiber Mats of Zinc-Oxide Loaded Polyacrylonitrile
}

\author{
S. K. Nataraj, B. H. Kim, J. H. Yun, D. H. Lee, T. M. Aminabhavi and K. S. Yang^ \\ Carbon Materials Lab, Alan G. MacDiarmid Energy Research Institute, Chonnam National University, Gwangju 500-757, Korea \\ •e-mail: ksyang@chonnam.ac.kr \\ (Received May 2, 2008; Accepted June 3, 2008)
}

\begin{abstract}
We have demonstrated the feasibility of using electrospinning method to fabricate long and continuous composite nanofiber sheets of polyacrylonitrile (PAN) incorporated with zinc oxide ( $\mathrm{ZnO})$. Such PAN/ZnO composite nanofiber sheets represent an important step toward utilizing carbon nanofibers (CNFs) as materials to achieve remarkably enhanced physico-chemical properties. In an attempt to derive these advantages, we have used a variety of techniques such as field emission scanning electron microscopy (FE-SEM), transmission electron microscopy (TEM) and high resolution X-ray diffraction (HR-XRD) to obtain quantitative data on the materials. The CNFs produced are in the diameter range of 100 to $350 \mathrm{~nm}$ after carbonization at $1000^{\circ} \mathrm{C}$. Electrical conductivity of the random CNFs was increased by increasing the concentration of $\mathrm{ZnO}$. A dramatic improvement in porosity and specific surface area of the CNFs was a clear evidence of the novelty of the method used. This study indicated that the optimal $\mathrm{ZnO}$ concentration of $3 \mathrm{wt} \%$ is enough to produce CNFs having enhanced electrical and physico-chemical properties.
\end{abstract}

Keywords : Electrospinning, Polyacrylonitrile, Nanofiber, Zinc oxide, Composites

\section{Introduction}

As a semiconductor material, zinc oxide spans a wide range of applications from solar cells and chemical sensors $[1,2]$ to electrical, acoustic, and luminescent devices [3-5]. Recently, zinc oxide $(\mathrm{ZnO})$ has attracted increasing interest due to its relatively high efficiency as a low-voltage phosphor. It is considered to be a promising phosphor for low-voltage luminescence in flat panel displays [6,7]. To keep abreast of the industry for flat panel displays and other optical devices, the luminescence efficiency of $\mathrm{ZnO}$ must be substantially improved [8]. Among the wide variety of semiconductor nanostructures, $\mathrm{ZnO}$ nanostructured widebandgap semiconductors are attractive for high-efficiency, short-wavelength optoelectronic nano-devices. This is due to their wide direct bandgap of $3.37 \mathrm{eV}$ at room temperature, their large excitonic binding energy as well as high mechanical and thermal stabilities. $\mathrm{ZnO}$ nanostructures are promising materials for field-emission displays owing to their stable field emission [9].

Carbon nanofibers (CNFs) have been recognized to be the unique forms of carbon materials. The diversity of CNFs has been recognized as variable alignments of the laminated $c$ plane layers along the fiber axis, which provided typically three types of CNFs such as platelet i.e., alignment perpendicular to the fiber axis, tubular i.e., alignment parallel to the axis and herringbone i.e., alignment angled to the axis
CNFs [10-13]. When considering their possible applicability in catalysis, electrochemical energy-storage systems, gas or liquid separations and storage, a simple and effective technique for lowering fiber diameter to ca. $100 \mathrm{~nm}$ and creating effective pores in a controllable fashion must be developed to maximize the large accessible surface area along with enhanced properties.

The polyacrylonitrile (PAN) has been attracted much attention, since it is commercially available in large quantities as a carbon fiber precursor [14]. PAN is an excellent carbon precursor whose controlled pyrolysis permits the fabrication of mesoporous carbons and CNFs via electrospinning [15-17]. Electrospinning is a nanofiber assembly technique that utilizes an external electrostatic field to generate high surface area on small fibers with diameters on the nanometer scale $[18,19]$. This publication presents a new approach toward the production of well-dispersed $\mathrm{ZnO}$ embedded electrospun CNFs of PAN. Direct assembly of the composite nanofibers into large-area sheets is achieved by collecting the nanofibers onto a rotating drum winder with a surface velocity larger than the velocity of electrospun nanofibers producing sheets of reasonably well-aligned nanofibers. Then by using the combined characterization techniques, we were able to provide structural, morphological and property evidence to illustrate the importance of the dispersion of $\mathrm{ZnO}$ in PAN with enhanced performance. 


\section{Experimental}

\subsection{Solution preparation and electrospinning}

PAN (molecular weight of $160,000 \mathrm{~g} / \mathrm{mol}$ ) and $N, N^{\prime}$ dimethylformamide (DMF $\geq 99.9 \%$ ) obtained from Aldrich (Milwaukee, USA) were used as received. Zinc oxide was procured from Aldrich (Milwaukee, USA). DMF solutions of PAN (10 wt $\%$ ) containing 1, 2 and $3 \mathrm{wt} \%$ of $\mathrm{ZnO}$ solutions in DMF were prepared at $60^{\circ} \mathrm{C}$. The homogeneous PAN solution containing $\mathrm{ZnO}$ was spun at room temperature to produce a mat by applying a voltage of $25 \mathrm{kV}$ keeping the tip-to-collector distance of $20 \mathrm{~cm}$ through the positively charged capillary using the electrospinning apparatus (NTPS-35K, NTSEE Co., Korea). The negative electrode was connected to the rotating drum winder to collect the fiber mat on an aluminum foil wrapped on the drum (diameter = $16 \mathrm{~cm}$ ) with a rotation speed of $350 \mathrm{rpm}$. The syringe pump was set at the flow rate of $4 \mathrm{~mL} / \mathrm{min}$.

The electrospun A3-sized $(297 \mathrm{~mm} \times 420 \mathrm{~mm})$ shiny white PAN-ZnO mat obtained was stabilized in atmospheric air at $280^{\circ} \mathrm{C}$ for $1 \mathrm{~h}$ at the heating rate of $1^{\circ} \mathrm{C} / \mathrm{min}$. The stabilized fiber mats were carbonized at the rate of $5^{\circ} \mathrm{C} / \mathrm{min}$ up to $1000^{\circ} \mathrm{C}$ in a tubular electrical furnace under an inert nitrogen atmosphere. Totally, three different CNF mats were spun containing 1, 2 and $3 \mathrm{wt} \%$ of $\mathrm{ZnO}$ designated as P-Zn-1, P$\mathrm{Zn}-2$ and $\mathrm{P}-\mathrm{Zn}-3$ respectively.

\subsection{Structural and morphological characterizations}

\subsubsection{Rheological measurements}

The viscosity of PAN solutions was measured in a Brookfield Viscometer (LVDVII+, STOUGHTON, MA, USA). Experiments were performed in the cup configurations. The material flow during electrospinning was determined using: $Q=\Delta P / R$, where $Q$ is flow rate, $\Delta P$ is pressure difference, and $R$ is resistance, equal to $8 \Delta \eta L / \Pi r^{4}$. Here, $L$ is length of the capillary, $r$ is radius of the capillary, and $\eta$ is viscosity of the polymer solution. To determine viscosity experienced during the fiber formation, shear rate, $\Psi$ of the system was calculated using: $\Psi=4 Q / \Pi R^{4}$. After studying the variations in flow rates, we have fixed the flow rates at a constant value of $4 \mathrm{~mL} / \mathrm{h}$.

2.2.2. Scanning and transmission electron microscopes

A field emission scanning electron microscope (Hitachi, S4700, Japan) was used to characterize the morphology of the CNFs produced. Samples were sputter coated with Au-Pd of approximately $10 \mathrm{~nm}$ thickness layer to reduce the charging and were examined at an accelerating voltage of $10 \mathrm{kV}$. TEM images were captured (JEL, JEM-2000 FXII, OXFORD) on a $\mathrm{Cu}$ mesh grid with Tungsten and LaB6 emitter of 0.14 line resolution. Micrographs were digitally scanned and recorded.

\subsubsection{Surface area measurement}

Specific surface area and pore size distributions of the CNFs were evaluated using Brunauer-Emmett-Teller (BET) equation (ASAP2020, Micromeritics, USA) after preheating the samples to $150^{\circ} \mathrm{C}$ for $2 \mathrm{~h}$ to eliminate the adsorbed water. Pore size distributions were determined by applying Density Functional Theory (DFT) to nitrogen adsorption isotherms at $350^{\circ} \mathrm{C}$ using the software ASAP2020.

\subsection{Thermal analysis}

Thermogravimetric (TGA) and differential thermal analysis (SDTA) thermograms of the CNFs were obtained in nitrogen atmosphere at the heating rate of $20^{\circ} \mathrm{C} / \mathrm{min}$ between $25^{\circ}$ and $1000^{\circ} \mathrm{C}$ using TGA (Mettler, STAR SW).

\subsection{X-ray diffractometry}

High resolution X-ray diffraction (HR-XRD) patterns were obtained using Rigaku DMax 1200 diffractometer on the carbonized mats. A voltage of $40 \mathrm{kV}$ and a current of $30 \mathrm{~mA}$ using $\mathrm{CuK} \alpha$ radiation $(\lambda=1.5418), 0.02^{\circ}$ and $2 \theta$ step at the dwell time of $5 \mathrm{~s} / \mathrm{step}$ was used. A Rigaku RU200 rotating anode generator equipped with a Stratton camera was used to acquire HR-XRD patterns. Nickel filtered $\mathrm{CuK} \alpha$ radiation was used at an accelerating voltage of $50 \mathrm{kV} / 170 \mathrm{~mA}$. The data were collected on a phosphor image plates and digitized using a molecular dynamics scanner.

\section{Results and Discussion}

\subsection{Solution viscosity}

Kim et al [20] first reported the CNFs of PAN containing $\mathrm{ZnCl}_{2}$ were better conductive up to $1.418 \mathrm{~S} / \mathrm{cm}$ for $1 \mathrm{wt} \%$

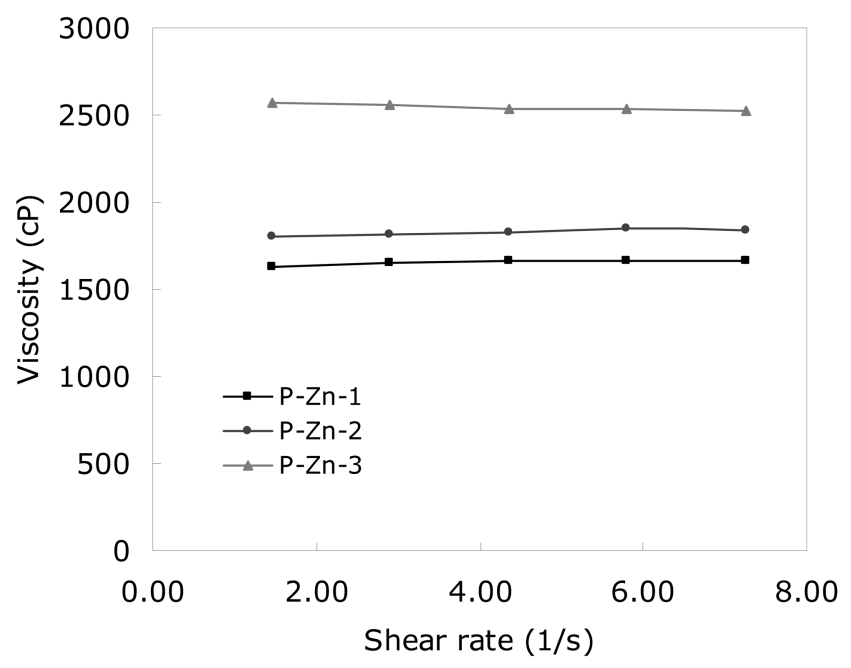

Fig. 1. Shear rate and viscosities of $1 \mathrm{wt} \%, 2 \mathrm{wt} \%$ and $3 \mathrm{wt} \%$ $\mathrm{ZnO}$ incorporated PAN solution. 
zinc chloride loading. Earlier we have reported the CNFs produced from solutions of PAN containing heteropolyacids [21]. In continuation of this program of study, in the present study, $\mathrm{ZnO}$ was used and it was found that for the first time CNFs could continuously, electrospun with high carbon yields and conductivities. In order to determine the optimal

Table 1. Solution Property and Surface Area Analysis Results of the PAN-ZnO-Based Composites Carbon Nanofiber

\begin{tabular}{cccccccc}
\hline Sample & SSA $\left(m^{2} g^{-1}\right)$ & TPV & $\mathrm{V}_{\text {micro }}\left(\mathrm{cm}^{3} \mathrm{~g}^{-1}\right)$ & $\mathrm{V}_{\text {meso }}\left(\mathrm{cm}^{3} \mathrm{~g}^{-1}\right)$ & APS $(\mathrm{nm})$ & $\begin{array}{c}\text { Solution } \\
\text { conductivity } \\
(\mu S / \mathrm{cm})\end{array}$ & $\begin{array}{c}\text { Solution } \\
\text { viscosity }(\mathrm{cP})\end{array}$ \\
\hline P-Zn-1 & 470 & 0.27 & 0.19 & 0.09 & 0.49 & 205 & 1635 \\
P-Zn-2 & 535 & 0.32 & 0.22 & 0.10 & 0.58 & 290 & 1820 \\
P-Zn-3 & 580 & 0.37 & 0.33 & 0.20 & 0.58 & 339 & 2210 \\
\hline
\end{tabular}

SSA-specific surface area determined by t-plot method.

TPV-total pore volume

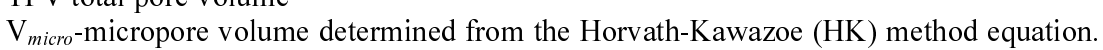

$\mathrm{V}_{\text {meso }}$-mesopore volume determined from the subtraction of micropore volume from total pore volume.

APS-Average pore size
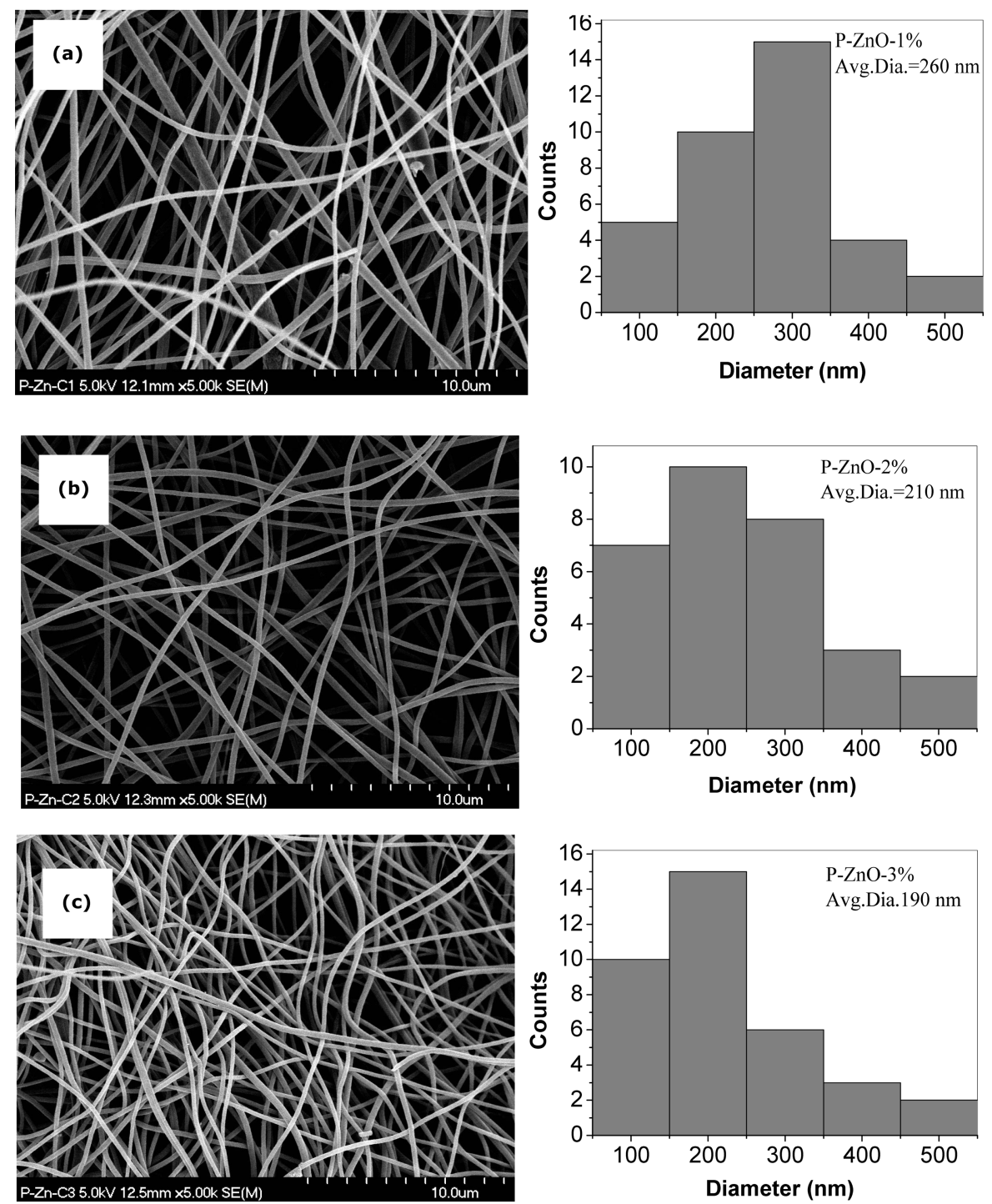

Fig. 2. FE-SSEM images and size distribution of PAN CNFs with (a) $1 \mathrm{wt} \% \mathrm{ZnO}$, (b) $2 \mathrm{wt} \% \mathrm{ZnO}$ and (c) $3 \mathrm{wt} \% \mathrm{ZnO}$ incorporated and carbonized at $1000^{\circ} \mathrm{C}$ in $\mathrm{N}_{2}$ atmosphere. 
concentrations of PAN solutions for electrospinning, various concentrations of $\mathrm{ZnO}(1,2$ and $3 \mathrm{wt} \%$ ) were tried and it was found that the CNFs produced with $3 \mathrm{wt} \%$ gave optimum physico-chemical properties with long and uniform diameter fibers without any beads, which is the minimal concentration required for suitable polymer chain entanglement that stabilizes the liquid that is ejected and allow the fibers to form as the solvent evaporates. The viscosity of the solution is an important parameter, indicating that the PAN solution is very stable during the electrospinning process. Fig. 1 displays the linear viscosity shear rate for all concentrations of PAN-containing $\mathrm{ZnO}$ particles. Fiber diameter is influenced by solution viscosity, since it is proportional to the jet length measured from the tip of the spinning drop to the onset of waves in the fiber [22,23]. In this work, it was observed that the fiber diameters increased with increasing in solution viscosity [24]. Also as reported in Table 1, the
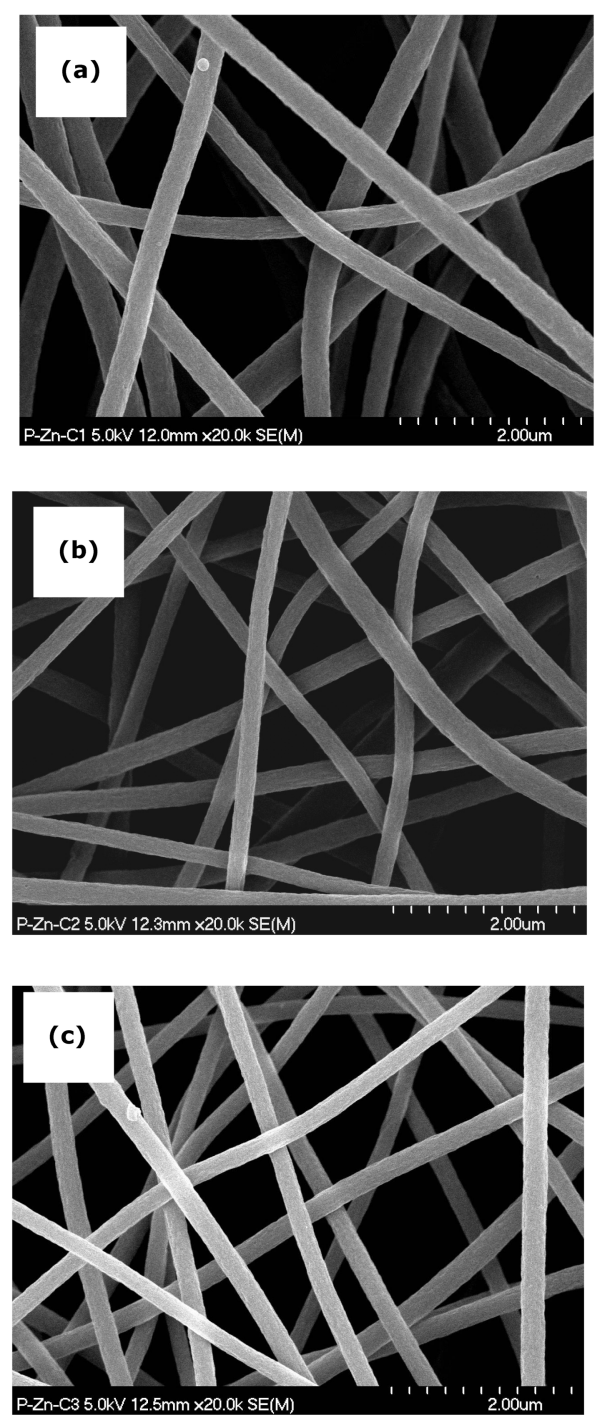

Fig. 3. FE-SEM images of $\mathrm{ZnO}$ incorporated $\mathrm{CNF}$ at higher magnifications and individual fibers with (a) $1 \mathrm{wt} \% \mathrm{ZnO}$, (b) $2 \mathrm{wt} \% \mathrm{ZnO}$ and (c) $3 \mathrm{wt} \% \mathrm{ZnO}$ incorporated and carbonized at $1000^{\circ} \mathrm{C}$ in $\mathrm{N}_{2}$ atmosphere.
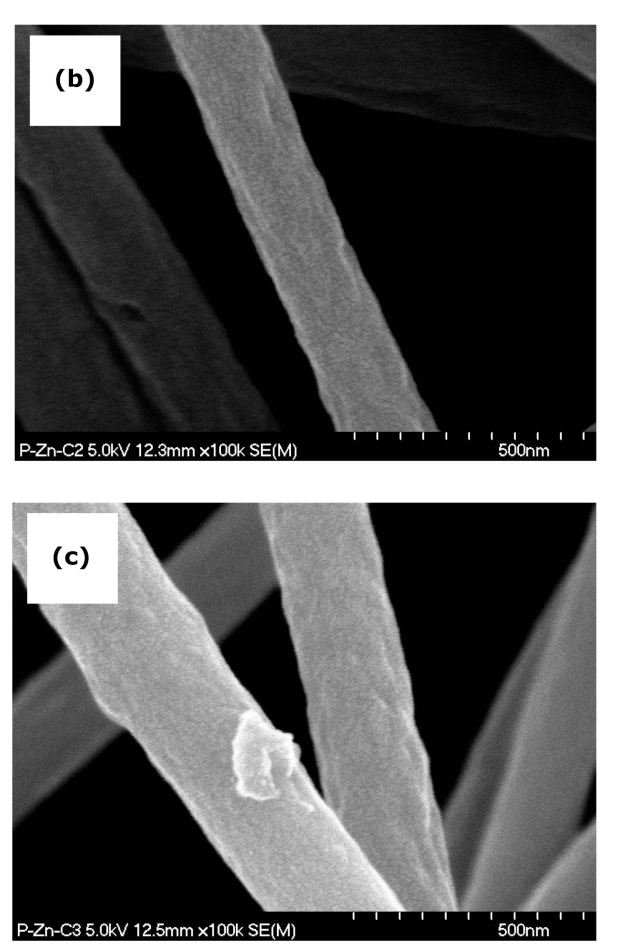

viscosities of PAN solutions increased with increasing concentration of $\mathrm{ZnO}$. Changes in viscosity of 1,2 and 3 wt $\% \mathrm{ZnO}$ loaded PAN solutions which increase with increasing concentration of $\mathrm{ZnO}$ in PAN solution. This is probably because of the expansion of PAN chain as the $\mathrm{ZnO}$ concentration increased. However, a significant increase in viscosity was observed for $3 \mathrm{wt} \% \mathrm{ZnO}$ containing PAN solution, which could be attributed to adsorption capacities of the exposed hydroxyl groups at the surface of CNFs. Notice that viscosity of the solution increased slightly with an increase in shear rate, suggesting that the rheological properties of PAN solutions follow the Newtonian trend.

\subsection{Surface characterization}

Surface characterization of the CNFs produced is not only important in understanding the surfaces, but also to estimate

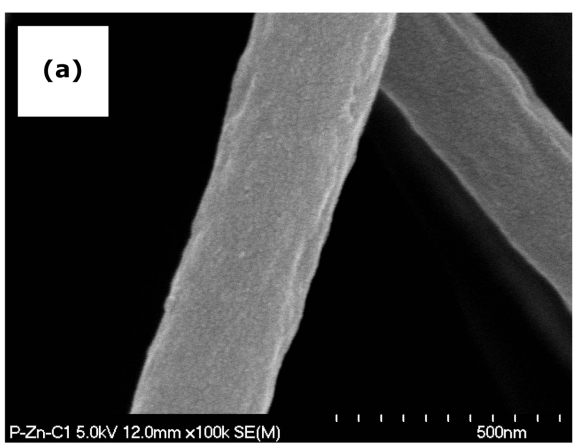


the interaction of $\mathrm{ZnO}$ particles with the PAN matrix. A quantitative estimation was established to conclude the results of surface characterization.

\subsubsection{SEM analysis}

SEM images of $\mathrm{PAN} / \mathrm{ZnO}$ composite carbonized at $1000^{\circ} \mathrm{C}$ in nitrogen atmosphere are shown in Fig. 2 with (a) $1 \mathrm{wt} \%$, (b) $2 \mathrm{wt} \%$ and (c) $3 \mathrm{wt} \%$ incorporation along with diameter distributions. Interestingly, it was found that the average diameters of the PAN nanofibers could be controlled by changing the concentration of the filler $\mathrm{ZnO}$, even though solution properties like viscosity, conductivity and surface tension are the main factors influencing the transformation of PAN solutions into CNFs. The SEM images of the PAN/ $\mathrm{ZnO} \mathrm{CNFs}$ have the diameters in the range of 100-350 nm and that the incorporated $\mathrm{ZnO}$ particles have created continuous rough surfaces of $\mathrm{CNF}$ consisting of large $\mathrm{ZnO}$ particles, as are shown by high magnification of individual nanofibers SEM in Fig. 3. We could notice the presence of $\mathrm{ZnO}$ particles adhering to the CNF surface along with some agglomeration due to the presence of $\mathrm{ZnO}$ particles. The diameters of the nanofibers have decreased with increasing concentration of $\mathrm{ZnO}$ in PAN solution. Thus, the addition of $\mathrm{ZnO}$ was found to be relatively more effective in controlling the fiber diameter than the other parameters described before. There, it can be concluded that the decrease in average fiber diameter of the fiber is mainly due to the increased charge density of the PAN solution at higher concentration of $\mathrm{ZnO}$ in PAN solution.

\subsubsection{TEM analysis}

TEM pictures shown in Fig. 4, confirm the presence of $\mathrm{ZnO}$ nanoparticles on the outer walls of CNFs. The $\mathrm{ZnO}$ nanoparticles are uniformly distributed throughout the fiber length, but still some particles remain on their surface. The size distribution of $\mathrm{ZnO}$ particles appears to be ranging from $10-15 \mathrm{~nm}$, size of the particle has increased with an increase in $\mathrm{ZnO}$ concentration.

\subsubsection{BET surface area}

Nitrogen adsorption isotherms of the activated $\mathrm{ZnO}$ containing CNFs reveal the differences in porosity. The distribution of pore volume with respect to pore size was captured for each concentration of $\mathrm{ZnO}$ in the PAN system at $1000^{\circ} \mathrm{C}$ from their $\mathrm{N}_{2}$ adsorption isotherms collected at 77 $\mathrm{K}$. Even with an the increase in porosity after the addition of $\mathrm{ZnO}$ filler was obtained, no significant increase in surface area was observed, probably due to simultaneous increase in average diameter of the activated CNFs (see data in Table 1). The specific surface area and micropore volume for P-Zn-1 are $470 \mathrm{~m}^{2} / \mathrm{g}$ and $0.19 \mathrm{~cm}^{3} / \mathrm{g}$, while for P-Zn-3 these are 580 $\mathrm{m}^{2} / \mathrm{g}$ and $0.20 \mathrm{~cm}^{3} / \mathrm{g}$, respectively. It is important to note here that a suitable amount of $\mathrm{ZnO}$ require to fabricating CNFs with optimal activation conditions such that the
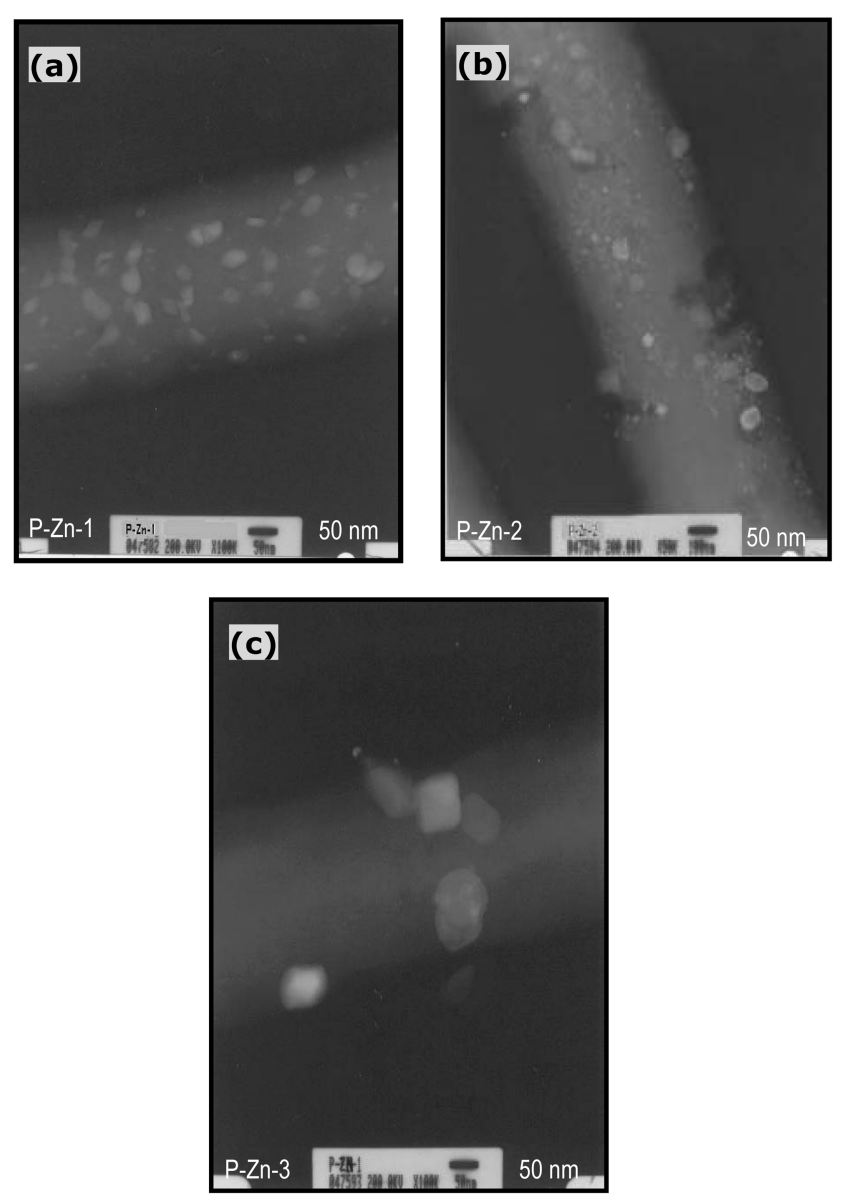

Fig. 4. FE-SSEM images of PAN CNFs incorporated with (a) 1 $\mathrm{wt} \% \mathrm{ZnO}$, (b) $2 \mathrm{wt} \% \mathrm{ZnO}$ and (c) $3 \mathrm{wt} \% \mathrm{ZnO}$; carbonized at $1000^{\circ} \mathrm{C}$ in $\mathrm{N}_{2}$ atmosphere.

micropores are formed and distributed throughout the matrix. At higher temperatures slight sintered oxide particles for higher loadings forms aggregates and on its way to migrating towards the surface might leave the pores like structure, wherein higher amount of the oxide particles produced a partially broken wall framework since the oxide particles might not be sufficient to sit on the fiber surface. These aggregates of particles sitting on surface are evident from SEM picture and forming some pores also can be seen from TEM resulting in the increased surface area.

\subsection{Thermal analysis}

The effect of temperature results in an interactions of $\mathrm{ZnO}$ with PAN matrix, which creates the additional microporosity to the composite matrix due to the activation process. Thermogravimetric analysis (TGA) and SDTA data recorded in the range of $25^{\circ}-1000^{\circ} \mathrm{C}$ under nitrogen gas flow at the rate of $10^{\circ} \mathrm{C} / \mathrm{min}$ are shown in Fig. 5(A) for PAN precursor. The residual weight remained the same at $1000^{\circ} \mathrm{C}$ due to the presence of $\mathrm{ZnO}$ particles in PAN nanofiber-matrix, which 

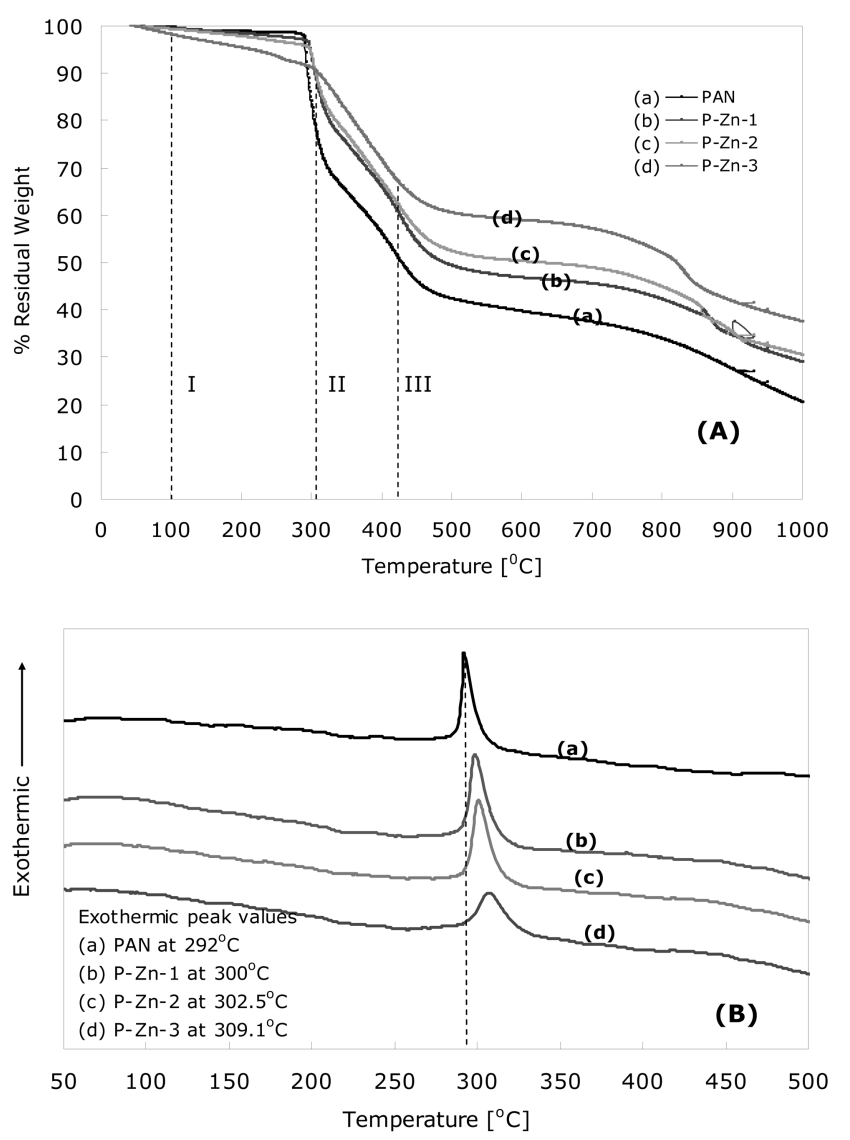

Fig. 5. (A) TGA and (B) SDTA curves of $1 \mathrm{wt} \%, 2 \mathrm{wt} \%$ and 3 wt $\% \mathrm{ZnO}$ incorporated nanofibers in $\mathrm{N}_{2}$ atmosphere.

increased with increasing amount of $\mathrm{ZnO}$ added. TGA and SDTA data of ZnO/PAN CNFs suggest the dehydration as confirmed by weight loss in the TGA curve. Fig. 5(B) displays the samples with different loadings of zinc oxide exhibited a strong exothermic peak corresponding to dehydration, cyclization, dehydrogenation and crosslinking of PAN matrix. Thus, decomposition PAN following the zinc oxide particles forming aggregates and was migrated towards the surface of CNF as observed in SEM images. In the present system, a sharp peak appeared at 292 for the PAN fiber, while exothermal peaks appeared at 300, 302.5 and 309.1 for $1 \mathrm{wt} \%, 2 \mathrm{wt} \%$ and $3 \mathrm{wt} \%$ for composites. With increase in zinc oxide content, the exothermic peak and its onset temperature shift to higher temperatures. This type shift attributed to physical-type of interactions between the PAN matrix and the filler $\mathrm{ZnO}$ particles that tend to reduce the PAN chain mobility, thereby increasing the $T \mathrm{~g}$.

\subsection{X-ray diffraction study}

High resolution X-ray diffraction (HR-XRD) was used to explore the relationship between spin process conditions and properties of the drawn fibers. PAN is an unusual polymer in

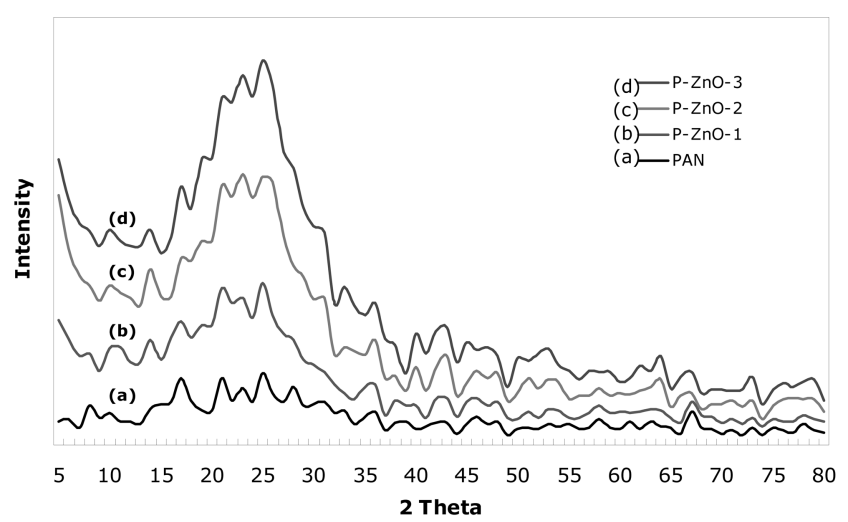

Fig. 6. X-ray diffraction patterns of CNFs having (a) PAN, (b) $\mathrm{P}-\mathrm{ZnO}-1 \mathrm{wt} \%$, (c) P-ZnO-2 wt \% and (d) P-ZnO-3 wt \%.

that even an atactic sample can be crystallized. It is clear that the pristine PAN shows typical peaks of PAN or graphite at $2 \theta=26.01^{\circ}$ and $44.42^{\circ}$, assigned to $(0,0,2)$ and $(1,0,0)$ planes, respectively. XRD of plain on $\mathrm{ZnO}$ is shown as curve at $(1,0,0),(0,0,2),(1,0,1),(1,0,2)$ and $(1,1,0)$ of plain $\mathrm{ZnO}$ were observed at $2 \theta=31.73^{\circ}, 34.35^{\circ}, 36.2^{\circ}, 47.47^{\circ}$ and $56.56^{\circ}$, respectively, as per earlier report $\mathrm{ZnO}$ [25]. Fig. 6 shows the XRD of PAN/ZnO composite subjected to heat treatment at $1000^{\circ} \mathrm{C}$ for different added concentrations of $\mathrm{ZnO}$ in the PAN. The $(1,0,0),(0,0,2),(1,0,1),(1,0,2)$ and $(1,1,0)$ planes of $\mathrm{ZnO}$ are observed at $2 \grave{e}=31.67^{\circ}$, $34.3^{\circ}, 36.14^{\circ}, 47.44^{\circ}$ and $56.51^{\circ}$, respectively. Moreover, the $(0,0,2)$ plane characteristic peak of graphite is observed at $2 \theta=26.01^{\circ}$. The, HR-XRD data are important in agreement with the draw ratio-induced orientation and crystallization when PAN fibers are oriented close to $T \mathrm{~g}$. From the XRD of PAN/ZnO composite $(1,0,0),(0,0,2),(1,0,1),(1,0,2)$ and $(1,1,0)$ planes of $\mathrm{ZnO}$ were observed at $2 \theta=31.67^{\circ}, 34.3^{\circ}$, $36.14^{\circ}, 47.44^{\circ}$ and $56.51^{\circ}$, respectively. Moreover, the $(0,0$, 2) plane characteristic peak of PAN can be observed at $2 \theta=26.01^{\circ}$.

\section{Conclusion}

PAN-ZnO composite carbon nanofibers have been successfully electrospun as continuous and long nanofibers. Composite nanofibers in the diameter range of 100-350 nm produced from in a highly aligned fashion. Electrospun fiber diameter depends greatly on solution viscosity as well as the concentration of the filler used. Using a variety of characterization techniques like FE-SEM, TEM, TGA and HR-XRD, we were able to characterize the CNFs to understand their morphological trends in terms of physicochemical properties. The experimental data presented here are the clear evidence of the methodology used for the dispersion of $\mathrm{ZnO}$ particles in PAN with enhanced performance. Thus, the present technique of fabricating thin, 
free-standing webs consisting of CNFs has technical merits and that these materials would replace the micrometer-sized activated carbon or activated carbon fibers in various electrochemical applications including fuel cells, where a large contact area between the electrode material and the electrolyte is required.

\section{Acknowledgements}

The authors thank MCIE, Korea, for financially supporting this research through "Technology Development for Future Generation". "This work was supported by the Korea Foundation for International Cooperation of Science \& Technology (KICOS) through a grant provided by the Korean Ministry of Science \& Technology (MOST) in K20602000009-07E0200-00910, BK21 and "Global Partnership Program (GPP)".

\section{References}

[1] Chopra, K. L.; Das, S. R. “Thin Film Solar Cells”, Eds. Plenum, New York, 1983.

[2] Muller, J.; Fresenius, S. W. J. Anal. Chem. 1994, 349, 380.

[3] Hingorani, S.; Pillai, V.; Kumar, P.; Multani, M. S.; Shah, D. O. Mater. Res. Bull. 1993, 28, 1303.

[4] Kong, L.B.; Li, F. Zhang, L.Y.; Yao, X. J. Mater. Sci. Lettr. 1998, 17,769.

[5] Shih, W.C., Wu, M.S. J. Cryst. Growth 1994,137,319.

[6] Troy, C.T. Photonics Spectra 1997,31,34.

[7] Vanheusden, K.; Seager, C. H.; Warren, W. L.; Tallant, D. R.; Caruso, J.; Hampden-Smith, M. J.; Kodas, T. T. J. Lumines 1997,75,11.
[8] Mo, C. M.; Li, Y. H.; Lin, Y. S.; Zhang, Y.; Zhang, L. P. J. Appl. Phys. 1998, 83, 4389.

[9] Li, Q. H.; Wan, Q.; Chen, Y. J.; Wang, T. H. Appl. Phys. Lett. 2004, 85, 636.

[10] Iijima, S. Nature 1991, 354, 56.

[11] Rodriguez, N. M.. J. Mater. Res. 1993, 8, 3233.

[12] Dekker, C. Phys. Today. 1999, 5, 22.

[13] Rodriguez, N. M; Chambers, A.; Baker, R. T. K. Langmuir 1995, 11, 3862.

[14] Jason, J. G.; Haoqing, H.; Qing, L.; Matthew, J.G.; Andreas, G.; Darrell, H. R.; Frank, W. H.; Stephen, Z. D. J. Am. Chem. Soc. 2004, 126, 15754.

[15] Kruk, M.; Dufour, B.; Celer, E. B.; Kowalewski, T.; Jaroniec, M.; Matyjaszewski, K. Chem. Mater. 2006, 18, 1417.

[16] Tang, C.; Qi, K.; Wooley, K. L.; Matyjaszewski, K.; Kowalewski, T. Angew. Chem. Int. Ed. 2004, 43, 3783.

[17] Chen, J. T.; Shin, K.; Leiston-Belanger, J. M.; Zhang, M.; Russell, T. P. Adv. Funct. Mater. 2006, 16, 1476.

[18] Reneker, D. H.; Chun, I. Nanotechnology 1996, 7, 216.

[19] Bognitzki, M.; Czado, W.; Frese, T.; Schaper, A.; Hellwig, M.; Steinhart, M.; Greiner, A.; Wendroff, J. H. Adv. Mater. 2001, 13, 70 .

[20] Kim, C.; Ngoc, B. T. N.; Yang, K. S.; Kojima, M.; Kim, Y. A.; Kim, Y. J.; Endo, M.; Yang S. C. Adv. Mater. 2007, 19, 2341.

[21] Nataraj, S. K.; Kim, B. H.; Yun, J. H.; Lee D. H.; Aminabhavi, T. M.; Yang, K. S. Synthetic Metals (Communicated, 2008).

[22] He, J. H.; Liu, H. M. Nonlinear Analysis 2005, 63, 919.

[23] He, J. H.; Wu Y.; Zuo, W. W. Polymer 2005, 46, 12637.

[24] Baumgarten, P. K. J. Coll. Interf. Sci.1971, 36, 71.

[25] Zhang, Y.; Lin, B.; Sun, X.; Fu, Z. Appl. Phys. Lett. 2005, 86, 131910. 